\section{Incessancy Of Education And Activities In The Development Of Professional Education}

\author{
Umarov Khusan Abdurakhimovich \\ Lecturer,Tashkent State Pedagogical University Named After \\ Nizami, Uzbekistan
}

\author{
G Open ACCESS \\ The American Journal of \\ Social Science And \\ Education Innovations \\ JULY 2020 \\ Page No.: 256-263 \\ Volume-II Issue-VII \\ PUBLISHED: 30 JULY 2020 \\ www.usajournalshub.com/inde \\ x.php/tajssei \\ Copyright: Original content \\ from this work may be used \\ under the terms of the \\ Creative Commons Attribution \\ 4.0 licence.
}

\title{
Abstract
}

This article discusses the problem of increasing the efficiency of the educational process through the use of practice-oriented methods in the organization of education in order to develop professional readiness.

Keywords: professional readiness, competence, improving of readiness, practice-oriented teaching, innovative approach to education.

\section{Introduction}

The active development of market relations in all spheres of professional activity has led to the emergence of a new factor in human labor activity - "the competitiveness of a specialist". The rapid growth in the volume and density of new knowledge and information flows accelerates the process of moral "obsolescence" of theoretical knowledge acquired in higher education, which is the main stage in the formation of the factor of personal readiness for professional activity.

Considering today's rapidly occurring globalization, the main attention is paid to 
ensuring that young people develop comprehensively, become a creative, physically strong and healthy generation, capable of combining their intellectual potential with physical maturity, raising their cultural, spiritual and educational level with national and universal values and knowledge.

To achieve these goals, the content of education is being modernized and, in order to create adequate conditions for the participants in the educational process, laws are being adopted and serious changes are being made to the education system.

The educator is a key figure in educational reform. As the well-known teacher K.D.Ushinsky said: "In education and upbringing, in general in school work, it is impossible to improve anything by going through the teacher's head." Consequently, it is inappropriate to expect results from reforms in the education system without teacher training, which plays an important role in enlightening the future generation of Uzbekistan, to professional pedagogical activity.

\section{The Main Findings And Results}

Modern pedagogical higher educational institutions are the basis for the education of future teachers, as well as their spiritual development. Therefore, in these educational institutions, not only the spirit of free scientific creativity should reign, but also students should be formed with diligence, curiosity, initiative, creative thinking and organizational qualities. As well as the consciousness of "future teachers", the ability to think independently, creativity, activity, deepening and enriching relationships are important qualities. And still all the factors influencing the formation and development of the need for self-control and education must be improved and enriched in content.

In this context, research aimed at increasing competitiveness through innovations in training, retraining workers and modernizing the education system is of particular importance.

With the change of time, the younger generation, its worldview and values are changing, which, in turn, makes new demands on the qualifications of teachers. At present, practical work on the training and qualitative transformation of pedagogical personnel is carried out in connection with a radical change in the content of higher 
pedagogical education. But, you cannot demand anything from a teacher that he was not taught, that he did not study. As a result, the introduction of new professional requirements for teachers, in turn, requires a different approach to the system of personnel training and the educational process in educational institutions with an emphasis on personnel training.

The theoretical knowledge gained by students in the educational process will undoubtedly become the basis of their professional skills. But at the same time, not only the knowledge of future teachers is important, but also the level of professional readiness. Confirmation of this can also be seen in the results of a number of recent studies conducted by local and foreign scientists. The result of these studies showed that they studied various aspects of the preparation of future teachers, but still insufficiently studied formal, non-formal and informal forms of education, and especially their continuity, as well as their integration with practical activities.

Today, in addition to the traditional functions of a teacher (education, upbringing, development, assessment, work with parents, etc.), from the point of view of modernization of education, such professional functions as forecasting and planning are relevant. Because modern education in a developing society should prepare highly qualified personnel who can independently make responsible decisions and understand the content of work. Thus, a modern teacher must have the knowledge and skills to carry out his professional pedagogical activity, as well as be able to analyze difficult situations, independently look for optimal ways to solve current problems, and see the prospects for his activities. This requires that the future teacher be adequately prepared for their professional activities.

An analysis of studies conducted by foreign and local researchers on the training of future teachers can lead to the following conclusion: "readiness is the ability of a specialist to find optimal solutions to various situations that may arise in his professional career, and to professionally perform any functional tasks".

A number of researchers in their studies called the level of training of a future teacher - competence. In their opinion, the quality of modern education is determined by the ability of graduates of educational institutions to identify the relationship between the 
knowledge gained and the situation and direct this knowledge to a professional solution of existing non-standard professional problems. This approach is viewed and analyzed as a competent approach.

Despite the fact that a considerable number of researchers have studied the problem of competencies, there is still a mistaken opinion among teachers that "competence is another name for the same knowledge, skills and abilities," and we do not agree with this opinion. We came to this conclusion after analyzing the scientific literature on this topic. The state educational standard of general secondary education of the Republic of Uzbekistan also defines a number of the following concepts: knowledge - memorization and re-interpretation of the information received; skill - to apply the acquired knowledge in familiar situations; ability - the ability to apply acquired knowledge and skills in unfamiliar situations and create new knowledge; competence - the ability to apply existing knowledge, skills and competencies in daily activities.

In addition, as evidence of our opinion, we can cite the work of some researchers: T.M. Bakikhina studied this issue and came to the conclusion that "Professional competence is the degree of a formed system of knowledge, skills, abilities, and individual initiatives necessary for effective implementation specific activity "[1]. The difference between competence and knowledge lies not only in knowledge about the activity, but also in its manifestation, the difference between competence and skill is that it can be applied to questions of different content. "The development of competence is assessed, first of all, by the end result (managed - failed to complete the task)" [2], which allows a person to act not only in their usual conditions, but also in new, non-standard conditions.

Some researchers believe that the concepts of "competence" and "competence" are synonyms that mean the same concepts. Regarding this issue, we agree with I.P. Medintseva, she explains these terms as follows: "competence (a set of interrelated personality traits set in relation to a certain range of objects and processes) and competence (possession, possession of a person of the appropriate competence, including his personal attitude to her and the subject of activity) ". [3]

Competencies are characterized by the following features:

- situational (appears only under certain conditions) 
- activity (only activity can be observed)

- personal orientation (depending on the individual characteristics and needs of a person)

- different stages (levels of competence are an indicator of quality that determines the level of development of a person's readiness to adequately respond to a situation)

Thus, we define competence as "the subject's ability to work with objects of activity or the subject's ability to effectively use previously acquired knowledge and skills in a particular situation, the ability to successfully carry out professional activities" and we decided to look at "competence" as an indicator of a future teacher's training.

However, this decision clarifies the problem of insufficient participation of students in practical activities in the educational process, which in some cases does not have sufficient opportunities for practical activities.

Despite the large number of scientific studies carried out by scientists on the relationship between science, education and industry, in universities in real life, technoparks, various subsidiary enterprises and manufacturing enterprises are insufficiently formed. This in turn leads to the assessment of practical skills again in the classroom - in a theoretical process.

It is clear that we will not be able to achieve the intended goal if we do not ensure continuity between production (which enables practical activity), which forms practical skills and education, which ensures the intellectual growth of the participant in the process. The reason is that knowledge is a product of intellectual activity, while training, on the contrary, manifests itself in practical activity. As a conclusion, we can say that it is necessary to develop a mechanism for determining the level of readiness of future personnel, their ability to fully meet the requirements of the employer, to develop a mechanism for testing the skills to perform professional activities at a high level.

It is no secret to anyone that the basic requirements of the employer begin with the fact that the staff has work experience. However, the lack of work experience of a specialist who has just started his career is obvious, and this is due to the fact that the employer does not need an inexperienced employee. 
Another aspect of the problem is the fact that pedagogical practice, which is the practical activity of the future teacher, is carried out at the end of the educational process and excludes the possibility of research or correction of any mistakes or omissions during practice.

As a solution to this problem, we recommend improving the learning environment by expanding its scope.

That is, in the learning process, students have the opportunity to spend their free time as a volunteer, trainee and intern (at industrial enterprises) to gain experience in their chosen field. This approach not only makes it possible to link the formal form of education with non-formal forms, but also allows young professionals to demonstrate their abilities in front of potential employers and further continue their professional career after training.

Analyzing the ways of organizing the process of formation and development of professional training of future personnel in this way, its stages can be defined as follows: The first stage is a scientific analysis of existing guidelines. The second stage is some changes in the existing system, new methods. The third stage is the complete development of the content, methods and forms of implementation of new ideas. The fourth stage is the development of new technologies and methods for teaching and educating future teachers.

However, it is becoming more and more obvious that in modern conditions, at a time when existing technologies and knowledge are rapidly updated and improved, it is impossible to train highly qualified personnel while staying inside the building of educational institutions. And yet, it should be noted that in order for the current education system to adapt to new requirements and serve as the basis for the formation of students' skills that meet the requirements of modern society, it should be borne in mind that applicants cannot always consciously choose the path of their future career and feel the need for its further improvement.

As said earlier, in many cases, the basic requirements of the employer begin with the work experience of the personnel. A serious requirement for the training of a future teacher in such conditions is not only the formation of knowledge and skills, but also the 
development of important professional qualities, the ability to seek and implement new approaches to education and upbringing. The reality is that university graduates are not sufficiently prepared to organize their professional activities. Therefore, it is necessary to think about the process of developing the professional competence of the future teacher, which is an indicator of his professional pedagogical training.

In the process of studying the problems of students' readiness, a number of reasons were identified that hinder their preparation at a high level. The experiment revealed that the main reasons for the relatively low level of training of students are:

1) partial inconsistency between the materials presented in the topic and with current situations;

2) problem situations * are not sufficiently relevant and their abstract nature, as well as separation from real life;

3) lack of motivation for education among students;

4) the prevalence of non-practical forms of education;

5 ) insufficient attention is paid to the organization of practical activities and independent work of students in the educational process. [4]

To solve these problems, you need to do the following: First: focus on the form of learning. It must be borne in mind that the content of education can be mastered only in the process of active activity of the subject, and organize the educational process on the basis of practice-oriented technologies. Secondly: the study of the content of the subject requires taking into account the presence of objects of research. To achieve this goal, great attention should be paid to practical developmental methods, such as practiceoriented interactive methods, problem situations, cases and much more. Third: content is related to teaching methods. In didactics, several forms of its presentation have been developed, each of which determines a specific program of educational and cognitive activity: verbal-descriptive, structural-conceptual, system-activity, and others. The latter plays a priority role in the organization of the educational process.

\section{Conclusion}

Studies have shown that in the preparation of future teachers, it becomes necessary to improve the mechanisms of interaction of the professional education system based on 
the content of educational programs and the environment of practical activity.

Accordingly, an improved model of mechanisms for the development of professional pedagogical training of future teachers was developed on the basis of the following principles:

1. Orientation of the content and forms of education to the individual;

2. Professional orientation of the content of the topic;

3. Complex thematic organization of educational material;

4. Consciously comparative study of topics;

5. Systemic variability of forms, methods and techniques of teaching;

6. Simulation is a professional adaptation of the game.

Such a system can teach students to form their roadmap for the consciously and independently (by themselves) development of their professional development, even in the early stages of learning.

\section{References}

1. TM Balykhina The content and structure of the professional competence of a philologist. Methodological problems of teaching the Russian language. Dis. for a job. uch.st. doct. ped. sciences. M .: 2000475 p., P. 59

2. OM Bobienko, ZN Safina Competence-oriented approach in adult education. Uch. a guide for teachers. Kazan: Ed. Center. Academy of Management "TISBI", 2004.204s.

3. I.P. Medintseva. Competence approach in education

Pedagogical skills: materials of the II Intern. scientific. conf. (Moscow, December 2012). URL: https://moluch.ru/conf/ped/archive/65/3148/ (date of access: 12.07.2020).

4. Mirsolieva MT Improving the mechanisms for developing the professional competence of managers and teachers of higher education institutions 13.00.07 Management in education Ped. fan.dok. (DSs) .diss. avtoref.-T .: 2019. 14 p. 